DOI: https://doi.org/10.24867/05FA03Zlatanovic

\title{
ARHITEKTONSKO-URBANISTIČKA STUDIJA TRANSFORMACIJE TRGA SVETOG TEODORA VRŠAČKOG, U VRŠCU
}

\section{ARCHITECTURAL AND URBAN STUDY OF THE TRANSFORMATION OF THE ST. TEODOR VRSACKI, IN VRSAC}

\author{
Ivana Zlatanović, Fakultet tehničkih nauka, Novi Sad
}

\section{Oblast - ARHITEKTONSKO I URBANISTIČKO PROJEKTOVANJE}

Kratak sadržaj - Ovaj rad bavi se arhitektonskourbanističkom studijom transformacije Trga Sv. Teodora Vršačkog, u Vršcu. U okviru ove celine sprovode se analize, utvrđuju se mane i potencijali postojećeg stanja. Nakon toga, uz pažljiv odabir metode za transformaciju urbanog gradskog prostora, pristupa se daljem rešavanju. Krajnji proizvod sadrži detaljne planove organizacije prostora sa uličnim mobilijarom $i$ raspredom zelenila. Cilj rada je da istakne jedinstven identitet prostora, iskoristiti sve njegove prednosti, $i$ stvoriti nove ambijentalne celine koje će zadovoljiti namenu samog trga. Prostor će postati atraktivniji za korisnike, ostvarujući nove, pristupačne ambijentalne celine, koji će privući što veći broj ljudi u kome će se oni osećati prijatno.

Abstract - This paper deals with the architectural and urban studies of the transformation of the square of St. Teodor Vrsacki, in Vrsac. The space was structurally analized, which lead to the establishment of its flaws and potentials. After that, along with the carefully chosen pragmatic metod for the transformation of the urban space, it was further approached to the solution. The final product should contain detailed plans for the space organization, as well as street furniture with the disposition of the plants. The goal was to accentuate the unique identity of the square, use all its potentials and create new ambiental spaces, which will satisfy the main funtional purpose of the plaza. It should be attractive to the users, create new and accessible spaces, which will attract more people who will enjoy in the given ambient.

Ključne reči: pejzažna arhitektura, urbanizam, trg, transformacija, centralna zona, javni prostori

\section{UVOD}

Trg kao arhitektonski urbanistički prostor ima manifestaciono pojavni oblik svima vidljiv i stalno prisutan. S obzirom da svaka forma kod posmatrača izaziva čitav spektar emocija, arhitektura se u tom svetlu saznanja nalazi u posebnom položaju. Poznavanje socijalne i kulturološke slike sredine je od vitalnog značaja kod odlučivanja, gde konzervativno društvo iziskuje i nalaže mnogo više opreza $u$ odnosu na otvoreno, $u$ procesu

\section{NAPOMENA:}

Ovaj rad proistekao je iz master rada čiji mentor je bila dr Mirjana Sekulić. donošenja rešenja koje podržava većinu funkcionalnoestetskih parametara, uz utkanu svežinu novog, koje neće uzurpirati postojeće svojom tektonskom nasrtljivošću.

\section{ODABIR TEME I CILJ ISTRAŽIVAČKOG RADA}

Trg Svetog Teodora Vršačkog je jednim delom manifestacioni trg, a drugim delom pešačko-trgovinski. Prema tome, njegovu formu i organizaciju je neophodno prilagoditi samoj nameni, ali na taj način da, osim što će zadovoljiti namenu, treba zadovoljiti i potrebe širokog dijapazona korisnika. Ovakvi javni prostori se ne mogu projektovati ni planirati za određenu ciljnu grupu. Prema tome, prostor se ne može u potpunosti programski definisati. $U$ toku projektovanja neophodno je uzeti u obzir sve vrste potencijalnih korisnika i kreirati jedinstvenu celinu koja će zadovoljiti njihove potrebe, a oni će je koristiti na načine na koje njima to najviše odgovara. Dakle, potrebno je isprojektovati adekvatan prostor koji će naglasiti njegov identitet, biti jedinstven, ali će se u isto vreme odlikovati i manjim celinama koje se međusobno razlikuju. Cilj ovog istraživanja je da se za početak usnove potencijali i nedostaci grada, koji će biti premisa daljem projektovanju. Novim rešenjem potrebno je unaprediti prostor $u$ smislu poboljšanja centralnog gradskog područja i javnog života u njemu, koji će se holistički integrisati u postojeće gradsko tkivo.

\section{PROCES TRANSFORMACIJE CENTRALNOG GRADSKOG PODRUČJA}

Transformacije i rekonstrukcije javnih gradskih prostora dešavaju se kada postojeći prostor (više) ne zadovoljava potrebe korisnika, tako da se može zaključiti da ovakve promene proizilaze iz dinamike grada. Moguće ih je realizovati na dva načina: kroz transformaciju već postojećih prostora, ili kroz formiranje potpuno novih.

\section{1. Čovek i prostor}

Prostor se može sagledati i doživeti na različite načine, što umnogome zavisi od osećaja subjekta koji ga posmatra, a projektant je onaj koji nameće tim subjektima kako će u njemu funkcionisati. Prilikom projektovanja, novim intervencijama ne treba narušiti postojeću gradsku koncepciju, već u skladu sa duhom datog vremena pokušati upotpuniti i uskladiti sa postojećim, i obezbediti prijatan boravak u njemu.

\subsection{Primenjena metodologija}

Da bi se došlo do rešenja određenog problema, potrebno je primeniti odabrane metode istraživanja $\mathrm{i}$ iz njih izvesti 
zaključke. Kako bi se obezbedili kvalitetni uslovi korisnicima jednog prostora, ove metode moraju biti pragmatične i funkcionalne u praksi.

Prilikom projektovanja, uzete su u obzir dve metode Jana Gela, iz njegove knjige „Gradovi za ljude“. Jedna je metoda „Okupljanje“, koja se sastoji od pet principa urbanističkog planiranja, a oni se odnose prvenstveno na broj korisnika, njihovo smeštanje, održavanje događaja i poboljšanje samog prostora i privlačenja ljudi. Druga metoda je „Grad u nivou oka“. Ovom metodom obuhvaćeno je dvanaeast kriterijuma kvaliteta podeljenih u tri grupe, koje bi jedan prostor trebao imati. Prva grupa obuhvata mere zaštite, druga se odnosi na komfor a treća na uživanje [2]. Upotrebom ovih metoda se mogu stvoriti uslovi za održiv prostor, koji ima svoj identitet i značajnu funkciju u socijalizaciji njegovih korisnika. Treba naglasiti lokalne vrednosti koje su deo identiteta prostora, stvoriti uslove za prijatan boravak, iskoristiti prednosti klimatskih uslova, voditi računa o meri čoveka i pružanju pozitivnog iskustva za sva čula.

\section{ISTORIJSKI RAZVOJ GRADA I GENEZA GRADSKOG TRGA}

Prvi pisani zapis o postojanju naselja datira iz 1227. godine. Vršački grad sa utvrđenjem je nastao 1332. godine, kao posledica neposrednih pretnji od turskih osvajanja, koji su osvojili mesto 1552. god. Skoro dva veka nakon toga, grad je oslobođen od turske vlasti, a Banat se priključuje Ugarskoj. U tom periodu doseljavaju se Nemci i Česi, kada grad počinje da menja svoju fizionomiju ka savremenom urbanizovanom naselju i doživljava procvat. Nove ulice seku se pod pravim uglom, formiraju se trgovi i podižu reprezentativna zdanja, a grad je podeljen na srpsku i nemačku opštinu.

Nakon Prvog svetskog rata, osetila se značajna stagnacija u razvoju. Tu se nadovezuje i svetska ekonomska kriza, pa Drugi svetski rat i veliki odliv nemačkog stanovništva. Obzirom na političku situaciju i blizinu granice, u Vršac se nije mnogo investiralo. Dosta kasnije, pojavljuje se industrijska zona koja unosi novi život u grad. Preduzimaju se veći urbanistički zahvati u gradu i pojavljuju se novi trgovi, zelene površine, parkinzi, hoteli i aerodrom.

Položaj trga u odnosu na grad najčešće je uslovljen genezom grada i njegovim spontanim razvojem. Povezanost sa putnim pravcima dovoza i odvoza robe, kao i prisustvo objekata trgovine i zanatstva svojevremeno su opredelili takvo rešenje neizgrađenog urbanog prostora. Glavni gradski trg, u prošlosti poznat kao „Markt-Platz“, prvobitno je bio u funkciji pijačnog prostora, oktužen kućama uglednih trgovaca.

Razvojem grada, pijačni prostor je izmešten, a ovaj prostor dobija funkciju trga. Kroz njega se uvodi kolska saobraćajnica i drvoredi, a trotoari se asfaltiraju za potrebe pešačkog saobraćaja. U međuvremenu je na tom prosturu izgrađena i autobuska stanica.

Sledećom rekonstrukcijom se zatvara saobraćajnica, a prostor postaje integralna celina $u$ vidu pešačke zone, kada se parkovska površina uklanja i zamenjuje popločanjem. Na trg je vraćen i spomenik „Krst“, na isto mesto na kojem je i bio u periodu funkcije trga kao pijačnog. Objekat autobuske stanice ostaje, ali se u prenameni utvrđuje kao komercijalni prostor. I pored toga što je pešačka zona definisana, ona i dalje nije prilagođena nameni prostora.

\section{ANALIZE POSTOJEĆEG STANJA}

Kroz analize postojećeg stanja istražena je dispozicija lokacije, dostupnost i funkcionisanje (u vidu sabraćajne analize i analize namene objekata blokova i površina), fizička struktura (kroz izgrađenost po horizontali i vertikali, i arhitektonske karakteristike), ekološki uslovi (ekološka analiza i uslovi insolacije) i sociološki uslovi.

Jedan trg, koji će funkcionisati u korist njegovih posetilaca, trebao bi biti prilagođen svima i human na prvom mestu, imati dovljan broj predviđenog (ali i nepredviđenog, sa mogućnošću korišćenja u te svrhe) prostora za sedenje, moraju postojati javni toaleti, hlad $u$ letnjem periodu, organizacija trga treba biti prilagođena nameni, mora postojati parking za motorna vozila, kao i parking za bicikle.

U postojećem stanju (Slika 1.) mogu se uočiti prednosti: lokacija trga, pristupačnost, velika površina, otvorena prizemlja i bogat program manifestacija. Problem kod ovog trga je to što je bezličan i ništa ne naglašava njegov identitet, nije prilagođen nameni, visokim krošnjama zaklonjene su vizure na objekte lepih fasada, sedenje je otuđeno, odnosno nema kolektivnih mesta socijalizacije, ne postoji javni toalet u čitavom gradu, a parking zauzima previše prostora.

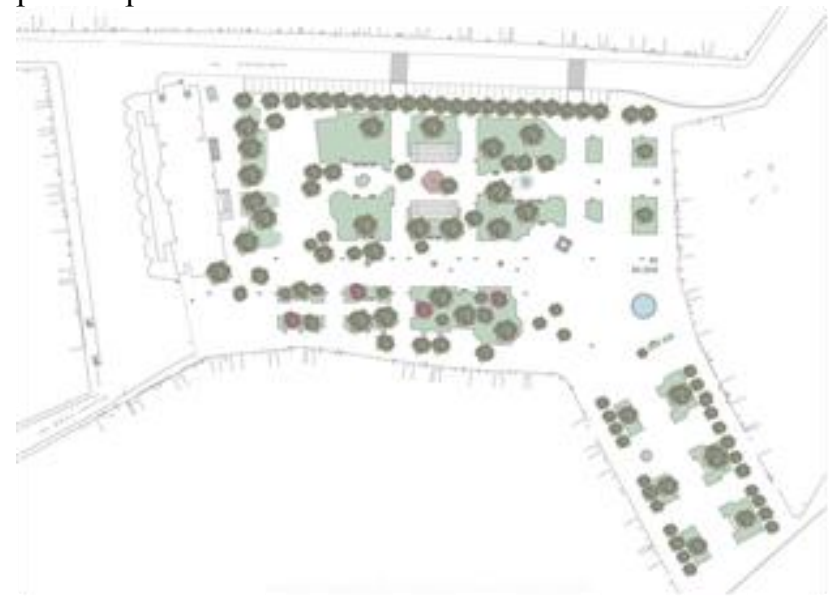

Slika 1. Plan postojećeg stanja

\section{PROJEKAT IDEJNOG REŠENJA TRANSFORMACIJE GRADSKOG TRGA}

\subsection{Konceptualizacija rešenja}

Centralno gradsko jezgro definiše identitet, kulturnu i socijalnu ulogu javnog prostora. Njegovom transformacijom stvara se novi odnos prostora i njegove funkcije, ističe se njegova funkcionalnost, pristupačnost i sociološke karakteristike.

Koncept oveg rešenja baziran je na kreiranju jednog javnog prostora koji obuhvata dve funkcionalne celine prve, manje, sa trgovinskim i ugostiteljskim sadržajima, i druge, znatno veće, sa istim sadržajima ali sa akcentom na njenu manifestacionu namenu. Ove dve celine iako imaju različiti karakter, upotpunjene su novim mikro celinama, gde su socijalni akspekt, pristupačnost i razumevanje funkcije na prvom mestu. A formiranjem i izmeštanjem postojećeg zelenila na adekvatnija mesta, otvaranjem 
fasada, uvođenjem multifunkcionalne platforme, vodinih površina, popločanja, podnog linijskog osvetljenja, urbanog mobilijara i uličnog osvetljenja, one su međusobno estetski povezane i objedinjuju se u jedan prostor.

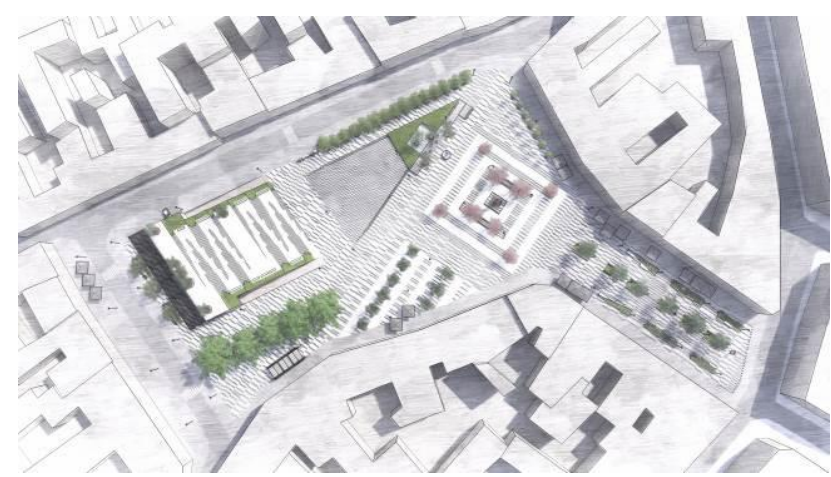

Slika 2. Plan novoprojektovanog rešenja

\subsection{Funkcionalna šema}

Parterno zelenilo u jugoistočnom delu trga je linijskog oblika, a prekinuto je na mestima koja su najprometnija pri kretanju korisnika. Fasade objekata su sada otkrivene, tako da doprinose prijatnijoj vizuri u ovom delu.

U zapadnom delu je uveden multifunkcionalni objekat/platforma, koji ima funkciju socijalizacije na njegovoj gornjoj površini, a ispod nje, smešten je javni toalet i parking prostor i galerija

U nastavku platforme, krećući se ka severoistoku, smešten je prostor koji je predviđen za održavanje redovnih manifestacija. On se nalazi par stepenika ispod nivoa terena, a iz pravca platforme deo ovog prostora je $\mathrm{u}$ nagibu, tako da formira rampu kako bi pristup na njega bio obezbeđen za sve kategorije posetilaca. U zimskom periodu, na ovom prostoru je planirano klizalište.

Nakon toga, nailazi se na zelenu i vodenu površinu, oko koje se nalazi mobilijar za sedenje i stara fontana, koja je ostala na istom mestu, tako da sve ukupno čini jednu mikro celinu sa vizurom na spomenik Krst, a u kombinaciji sa prisutnom vodom stvara prijatan ambijent. Centralni deo kod „Krsta“ koji je već u praksi Vrščana jedna od najpopularnijih repernih tačaka, u novoprojektovanom rešenju nalazi se i dalje na istoj lokaciji, a prostor oko njega je slobodan, kako bi se spomenik više naglasio i bio saglediv iz svih delova trga. $\mathrm{Na}$ obodima trga je isplaniran parter sa drugačijim popločanjem, koji je širine $5 \mathrm{~m}$, a namenjen je prolazu vozila za dopremanje robe u ugostiteljskim i trgovinskim objektima i za postavljanje letnjih bašti prisutnih kafića.

\subsection{Objekat/platforma}

Sa lokacije ovog objekta moguće je sagledati deo Vršačkih planina, tako da je to bila inspiracija za projektovanje objekta sa prohodnom gornjom površinom $\mathrm{u}$ nagibu, sa koje bi se ta vizura mogla naglasiti. Platforma je prohodna za pešake i prilagođena je i korisnicima sa invaliditetom $u$ vidu rampe koja se prožima kroz stepenice po čitavoj površini. Najviša tačka objekta je na visini od $4 \mathrm{~m}$. Ispod nje se u jednom delu nalazi javni toalet, čiji je ulaz vešto zaklonjen da ne bi narušavalo atmosferu trga, a do njega se dolazi rampama koje se nalaze sa leve i desne strane objekta. Pristup parking prostoru je u vidu rampe, koja počinje iz pravca ulice na severoistoku. Korisnici parkinga na površinu trga mogu izaći liftom koji vodi direktno do trga, ili stepenicama koje izlaze na pomenutu rampu sa južne strane platforme. Ispod najvišeg dela platforme isplaniran je prostor koji je namenjen potrebama gradskog muzeja.

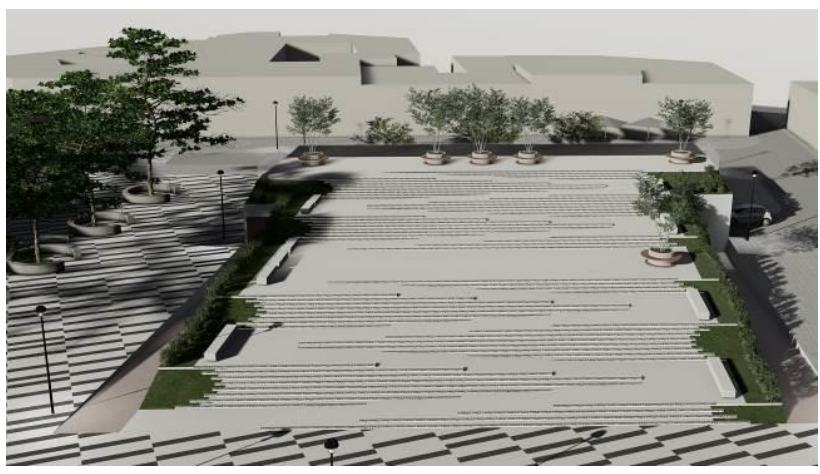

Slika 3. Platforma

\subsection{Zelenilo, vodene površine, popločanje}

Trg ima evidentan problem sa neadekvatnim vrstama visokog rastinja i njihovom dispozicijom i loše organozovanoim parternim zelenilom, zbog kojeg nema dovoljno prostora za održavanje manifestacija. Svaki segment trga, u zavisnosti od funkije, drugačijeg je karaktera i korišćene su različite vrste drveća. Karakteristična za čitav trg je šema popločanja, koje je u dve boje, s tim što se svetlija boja u dva osnovna segmenta trga razlikuje u nijansi, dok je tamnija ista, tako da ih to $\mathrm{u}$ isto vreme povezuje ali i razdvaja.

Jugoistočni segment trga (Slika 4.) karakterišu listopadne vrste drveća sa krošnjama koje nisu guste, ali stvaraju dovoljnu zaštitu od uticaja vetra i sunca. Organizovano je linijski u centralnom delu, tako da ne zaklanja fasade.

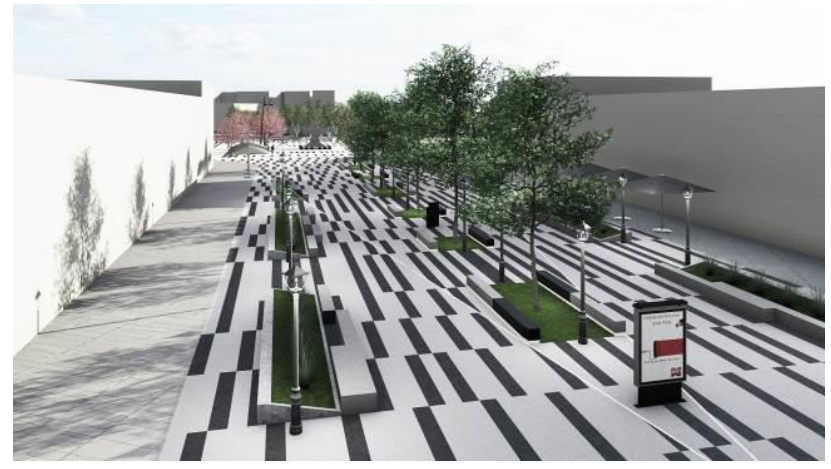

Slika 4. Jugoistočni segment

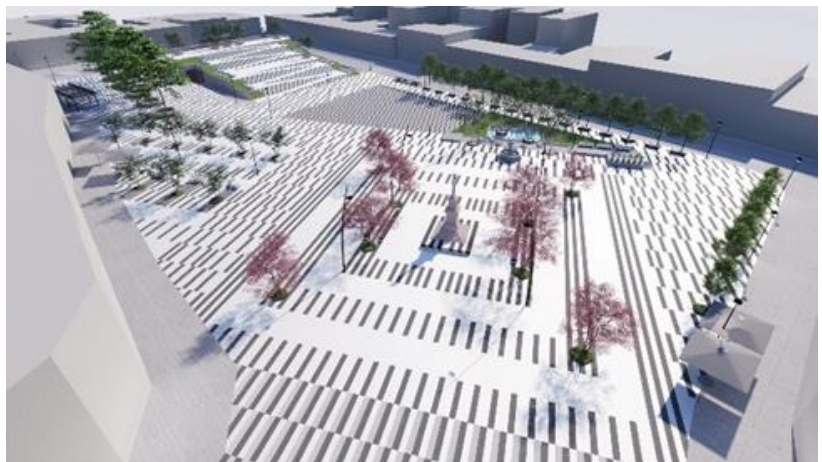

Slika 5. Centralni deo 
Centralni segment oko „Krsta“ (Slika 5.) nema parternog zelenila, jer je u tom delu potreban slobodan prostor za smeštanje ljudi i štandova u vreme manifestacija. Oko spomenika je isplanirano ukrasno crvenolisno drveće $u$ skladu sa samim spomenikom koji je od crvenog mermera. Ova celina razlikuje se od ostatka i u načinu popločanja, koje dodatno naglašava spomenik.

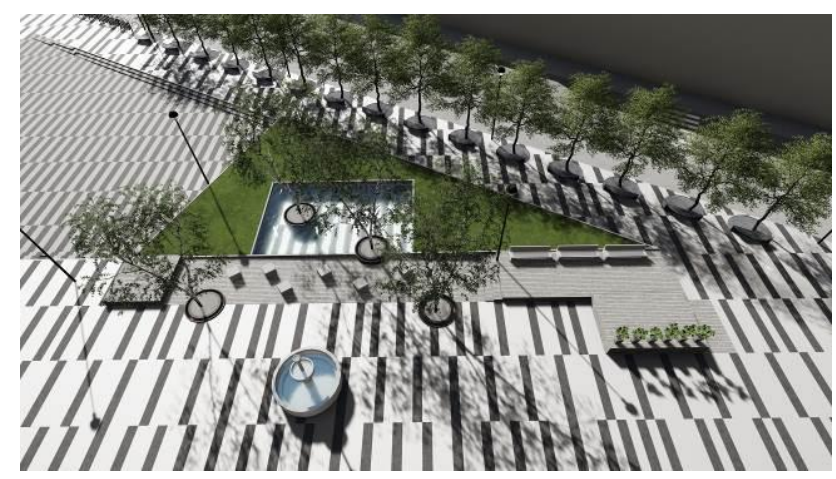

Slika 6. Severni deo trga

Postojeća fontana (Slika 6.) je zadržana, kao i drveće u njenoj neposrednoj blizini. Uvedena je manja vodena površina pored fontane, koja će vizurom i zvukom doprineti ambijentu ove mikro celine.

Naspram nje nalazi se jedna manja celina (slika 7.) koju karakteriše drveće niskog rasta postavljeno $u$ dve paralelne linije. Ova celina predstavlja jedan mikro ambijent za socijalizaciju, koji je dodatno naglašen i odvojen od ostatka u vidu drugačijeg načina popločanja i trakastog podnog osvetljenja.

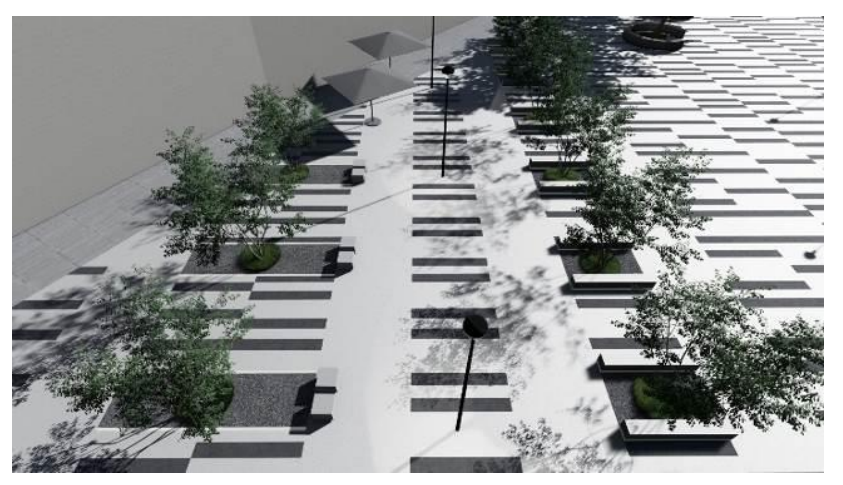

Slika 7. Ambijent

Najviše drveće na trgu nalazi se u jugoistočnom delu. U pitanju je pet stabala koja su takođe postavljena linijski, a od kojih su tri zadržana sa postojećeg stanja.

Platforma je na obodu ukrašena žbunastim rastinjem koje je tu predviđeno iz bezbednosnih razloga. Drveće na platformi se nalazi u posudama $\mathrm{i}$ ima ih šest.

\subsection{Mobilijar}

Mobilijar na trgu je prisutan u svim delovima $\mathrm{u}$ vidu sedenja, ulične rasvete, kanti za otpatke, stubićima kao graničnicima trotoara i parkinga za bicikle, a razlikuje se $\mathrm{u}$ odnosu na ambijent $\mathrm{u}$ kojem se nalazi. Osim ovih detalja, uvedena je diskretna česma za osveženje u letnjem periodu.

Jugozapadni segment (Slika 4.) ima specifičan karakter. Ulična rasveta je u vidu kandelabra, koji su od ranije bili karakteristični za gradski trg. Takođe, prožima se i u vidu podnog linijskog osvetljenja, kao i osvetljenja na donjoj ivici mobilijara za sedenje. Klupice su usklađene sa popločanjem po boji i dimenzijama, tako da izgleda kao da one ,izlaze“ iz njega.

$\mathrm{Na}$ ostatku trga zastupljeni su ,moderniji“ modeli rasvete. Oko „Krsta“ (Slika 5.) su u pitanju visoke svetiljke koje će bacati dovoljno svetlosti na njega i samim tim ga i akcentovati. I ovde iz popločanja ,,izlaze“ klupe koje su orijentisane ka spomeniku.

U segmentu u kojem je prisutna voda, (Slika 6.) oseća se drugačiji ambijent. Na parteru u vidu popločanja javlja se i drvo, koje je u nekim delovima nivelisano tako da se na njemu može sedeti, ili će služiti da se korisnici popnu na sledeći nivo. Ovaj segment je predviđen za grupne socijalizacije. Odmah pored ovog segmenta se nalazi postojeći drvored koji je zadržan, a ispod svakog drveta je smeštena po jedna klupa (Slika 6.).

Stepenice na platformi su predviđene kao potencijalno mesto za sedenje u vreme manifestacija, za veće grupe posmatrača. $\mathrm{Na}$ njoj su na bočnim ivicama prisutne i klupe, a na mestima sa drvećem i posudama, klupe su kružne.

Sledeći mikro ambijent (Slika 7.), osim drugačijeg načina popločanja, karakteriše i sedenje pozicionirano u blizini drveća, kako bi se obezbedila zaštita od sunca.

Kako je navedeno u jugozapadnom delu nalazi se pet stabala koja su najviša na trgu, a neka od njih su zadržana sa postojećeg stanja. Oko svakog stabla je postavljena kružna klupica, koja se može koristiti i kao orijentisana ka stablu, za korisnike koji žele malo privatnosti, ili orijentisana ka trgu sa vizurom na njega.

\section{ZAKLJUČAK}

Projekat transformacije Trga Sv. Teodora Vršačkog u Vršcu, rezultat je istraživačkog rada i primene metoda za poboljšanje urbanog gradskog prostora, koji će obezbediti kvalitetan boravak korisnicima na trgu. Raznolikost mikro celina, koje su prostorno i vizuelno povezane u jednu, daje priliku za uživanjem u različitim ambijentima, u zavisnosti od potreba. Predstavljeno rešenje novoprojektovanog trga sa multifunkcionalnim objektom pomoći će u afirmaciji socijalizacije i boravka na javnom gradskom prostoru.

\section{LITERATURA}

[1] A. Rossi, “Arhitektura grada”, Psefizma, Pinter design, Zagreb, 1999. Strana 32.

[2] C. Norberg - Schulz "Egzistencija, prostor $i$ arhitektura”, Građevinska knjiga, Beograd, 2006.

\section{Kratka biografija:}

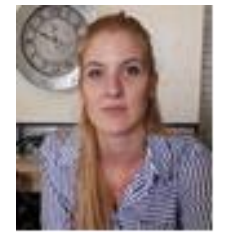

Ivana Zlatanović, rođena je u Vršcu 1993. god. Master rad na Fakultetu tehničkih nauka iz oblasti Arhitektonsko i urbanističko projektovanje - Pejzažna arhitektura odbranila je 2019.god.

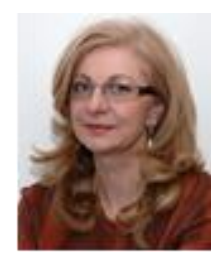

Dr Mirjana B. Sekulić, rođena je u Zemunu 1955. god. Doktorirala je na Fakultetu tehničkih nauka 2013. god, a od 2019. god. je u zvanju vanrednog profesora. Oblast interesovanja je pejzažna arhitektura. 